\title{
An Increase in Tryptase on the First Day of Hymenoptera Venom Immunotherapy Might Be a Predictor of Future Systemic Reactions During Treatment
}

\author{
Vega-Castro $\mathrm{A}^{1}$, Alonso-Llamazares $\mathrm{A}^{2}$, Cárdenas $\mathrm{R}^{1}$, Beitia $\mathrm{JM}^{1}$, Mateo $\mathrm{B}^{1}$, Alvarez-Twose ${ }^{3}$, Blanco $\mathrm{C}^{4}$
}

'Allergy Service, Hospital Universitario de Guadalajara, Spain

${ }^{2}$ Allergy Service, Hospital de Basurto, Bilbao, Spain

${ }^{3}$ Mastocytosis Institute, Toledo, Spain

${ }^{4}$ Allergy Service, Hospital de la Princesa, Madrid, Spain

J Investig Allergol Clin Immunol 2018; Vol. 28(5): 305-311

doi: 10.18176/jiaci.0258

\begin{abstract}
Background: Serum tryptase (ST) decreases during long-term venom immunotherapy (VIT). ST also exhibits a circadian variation, with a small decrease after sting challenge. Both findings have been related to successful VIT.

Objective: To assess whether variation (increase or decrease) in ST on the first day of VIT is associated with the likelihood of future systemic adverse reactions (SARs) during treatment.

Methods: We prospectively studied patients who underwent cluster VIT, which was continued for at least 6 months. ST was measured on the first day of VIT, before the first dose (pre-IT tryptase) and after the last dose (post-IT tryptase). Differences between patient groups (with and without SAR) were analyzed.

Results: A total of 160 courses of VIT were administered to 150 patients. The median baseline ST value was $4.3 \mu \mathrm{g} / \mathrm{L}$. A total of 25 courses $(15.6 \%)$ were associated with SAR. In 64\% of the 25 patients with SAR, the post-IT tryptase value was higher than the pre-IT tryptase level; the median increment was 19\% in these patients. We found a significant association between the increase in ST on the first day of VIT and future SARs (risk ratio, 7.6). This elevation was independent of the scheduled VIT day, severity of the SAR, and baseline ST value. Conclusions: A slight increase in tryptase on the first day of VIT is an independent variable that is strongly related to a high risk of future SAR. This simple biomarker could improve patient safety.
\end{abstract}

Key words: Venom immunotherapy. Tryptase. Hymenoptera allergy. Immunotherapy adverse reactions. Systemic mastocytosis.

\section{Resumen}

Antecedentes: Se ha observado una disminución progresiva del nivel de triptasa sérica (TS) basal durante la inmunoterapia con veneno de himenópteros (ITVH), así como la conservación de la variación circadiana de triptasa en pacientes que han tolerado una repicadura controlada. Ambos hallazgos se han relacionado con la eficacia del tratamiento.

Objetivo: Estudiar si la variación (aumento o disminución) de la TS durante el primer día de ITVH se relaciona con un mayor riesgo de presentar reacciones adversas sistémicas (RAS) con futuras dosis de ITVH.

Método: Estudio prospectivo de pacientes sometidos a ITVH en pauta de inicio agrupada y que continuaron con el tratamiento durante al menos 6 meses. Se determinó la TS el primer día de ITVH, antes de la primera dosis (triptasa pre-IT) y tras la última dosis (triptasa post-IT). Se analizaron las diferencias entre los dos grupos de pacientes (con o sin RAS).

Resultados: Se administraron 160 ITVH a 150 pacientes. El valor medio de TS basal fue 4,3 $\mathrm{gg} / \mathrm{L}$, siendo $>11,4 \mu \mathrm{g} / \mathrm{L}$ en 4 casos. Un total de 25 ITVH (15,6\%) presentaron RAS. En 64\% de los 25 pacientes con RAS, el valor de triptasa post-IT fue más alto que el valor de triptasa pre-IT; el incremento medio fue del $19 \%$ en estos pacientes. Encontramos una relación significativa entre este aumento de triptasa el primer día de ITVH y la aparición de RAS con futuras dosis de ITVH (risk ratio 7,6). Esta elevación fue independiente del día de aparición de la reacción, de la gravedad de la misma, así como del valor basal de triptasa.

Conclusiones: Un ligero aumento de triptasa el primer día de ITVH es una variable independiente, fuertemente relacionada con un alto riesgo de presentar una futura RAS. Este sencillo biomarcador podría ser útil para mejorar la seguridad de estos pacientes.

Palabras clave: Inmunoterapia con veneno de himenópteros. Triptasa. Alergia a himenópteros. Reacciones adversas con inmunoterapia. Mastocitosis sistémica. 


\section{Introduction}

Tryptase is a chemical mediator produced and secreted by mast cells. Baseline serum tryptase (ST) level correlates with body mast cell load and, in acute allergic reactions, provides a measure of mast cell activation [1]. Several authors have reported an association between hymenoptera venom allergy and elevated baseline ST. Higher levels have been associated with the presence of systemic mastocytosis (SM), clonal mast cell activation disorders (cMCAS) [2], a risk of severe hymenoptera sting reactions $[3,4]$, lower efficacy of venom immunotherapy (VIT) [3], and an increased incidence of adverse reactions to VIT [5].

It has been reported that the baseline ST level in patients receiving VIT decreases by $2.5 \%$ per year [6], although the natural tendency in the healthy population is toward a slight increase with age. The ST concentration also seems to exhibit a circadian variation, with slightly higher values in the morning. In this context, a temporary increase in ST in patients who developed systemic reactions after sting challenge has been reported [7]. Consequently, the presence of this slight decrease in baseline ST concentration in patients receiving VIT, in both the long term and the short term, has been associated with successful treatment.

Subcutaneous VIT is highly effective, with a rate of protection against new sting-induced anaphylaxis of around $85 \%-98 \%$ of people treated [8]. Despite this efficacy, systemic adverse reactions (SARs) are common. The rate of SARs with VIT is between $5 \%$ and $40 \%[9,10]$, with one-fifth being severe. The major risk factor associated with SAR is honeybee VIT $[11,12]$. Other factors that are potentially related to an increased risk of SAR include female gender [11], ultrarush protocols [11,12], antihypertensive therapy [12], high basophil allergen sensitivity, Api m 4 sensitization [13], and a short interval between insect sting and onset of symptoms [14].

This study was designed to investigate a possible relationship between variation in ST levels in response to initial VIT doses and the development of future SARs during long-term VIT.

\section{Material and Methods}

We performed a prospective study in the Allergy Section of University Hospital of Guadalajara, Guadalajara, Spain. The period of analysis was from January 2008 to April 2016. The study was approved by the local ethics committee.

\section{Patients}

Patients of any age diagnosed with hymenoptera venom allergy who agreed to start VIT and continue receiving it for at least 6 months were included. Patients who dropped out before month 6 of VIT without having experienced a SAR were excluded.

Hymenoptera venom allergy was diagnosed according to the recommendations of the European Academy of Allergy and Clinical Immunology [15] in their recent guidelines [16] and was based on a detailed clinical history and a complete allergy work-up performed at least 4 weeks after the sting reaction.
The allergy work-up comprised skin prick and intradermal tests for the main hymenoptera venoms (Apis mellifera, Vespula species, and Polistes dominula [ALK-Abelló]), baseline ST (ImmunoCAP tryptase, Thermo Fisher), total IgE (Immulite 2000, Siemens Diagnostics), and specific IgE to Apis species, Vespula species, and Polistes dominula (ImmunoCAP, Thermo Fisher). Patients' clinical and demographic characteristics were collected.

In the case of suspected mast cell disease, a complete bone marrow study was performed to diagnose SM according to the current World Health Organization (WHO) criteria [17] and cMCAS according to published proposals $[2,18,19]$. The REMA score was used as a screening tool for cMCAS [19].

\section{Venom Immunotherapy}

VIT was administered following the recommendations of the European Academy of Allergy and Clinical Immunology subcommittee on insect venom allergy [9] using Apis mellifera, Vespula species, or Polistes dominula venom (Pharmalgen [ALK-Abelló] or Albey [Stallergenes]) according to the individual sensitization profile. Patients received subcutaneous VIT using a build-up cluster schedule [20] (Table 1) comprising several doses per day within a 30-minute interval on 2 nonconsecutive days until a $100-\mu \mathrm{g}$ dose was reached. This maintenance dose was then administered monthly during the first year and subsequently at increasing time intervals (every 6-8 weeks) until 5 years of treatment were completed. Patients were not pretreated with antihistamines before VIT doses.

All VIT doses were administered in a hospital setting by personnel trained in early recognition and treatment of adverse reactions. On the day of VIT administration, doses and adverse reactions were recorded. SARs were graded in accordance with the World Allergy Organization (WAO) classification as reported by Cox et al [21]. Management of SAR also followed established WAO recommendations [22]. In patients who experienced a SAR, pretreatment with antihistamines (alone or combined with oral corticosteroids) was administered before subsequent doses.

\section{Measurement of Serum Tryptase}

Blood samples were obtained on the first day of VIT to measure tryptase before the first dose (pre-IT tryptase) and 90-120 minutes after the last dose (post-IT tryptase).

Table 1. VIT Cluster Build-up Schedule

\begin{tabular}{lc}
\hline & Venom Dose, $\mu \mathrm{g}$ \\
\hline Day 1 & 5 \\
& 10 \\
& 20 \\
& 20 \\
Day 8 & 50 \\
& 50 \\
Day 22 & 100 \\
\hline
\end{tabular}

Doses were administered at 30-minute intervals on days 1 and 8 . 
Both serum samples were stored at $4^{\circ} \mathrm{C}$ when measurements were performed on the same day or at $-20^{\circ} \mathrm{C}$ if the analysis was performed on another day. The time interval between the 2 blood draws was 3-3.5 hours (first blood sample at 08:30-09:00 hours and the second at 11:30-12:00 hours). Both serum samples were analyzed simultaneously in the same assay (ImmunoCAP Tryptase, Thermo Fisher). SARs and their association with patients' baseline tryptase, pre-IT tryptase, and post-IT tryptase levels were evaluated. Tryptase concentrations exceeding $11.4 \mu \mathrm{g} / \mathrm{L}\left(95^{\text {th }}\right.$ percentile for healthy nonallergic individuals, as determined by the manufacturer) were considered elevated. The interassay variability of the tryptase technique was estimated to be $\leq 5 \%$ (manufacturer's data).

\section{Statistical Analysis}

Quantitative variables are presented as median (IQR). Categorical variables are shown as percentages. Bivariate analyses were performed using the $\chi^{2}$ test and the MannWhitney test for assessing differences between groups with and without SAR. $P$ values less than .05 were considered significant. When significant differences were found, the risk ratio (RR) was estimated. All statistical analyses were performed using IBP SPSS Statistics for Windows, Version 20.0 (IBM Corp).

\section{Results}

\section{Sample Profile}

Patients

A total of 155 patients started VIT. Five patients were excluded: 2 dropped out before month 6 of VIT without having had a SAR, and the other 3 had received VIT for less than 6 months at the end of the study. The final sample comprised 150 patients (106 men and 44 women, with a median age of 45 years [35-55.7 years]). Nine patients were diagnosed with SM or cMCAS $(6 \%$; 95\%CI, 2.2\%-9.8\%). Clinical and demographic data are summarized in Table 2.

\section{Baseline tryptase}

The median baseline tryptase value of the sample was $4.3 \mu \mathrm{g} / \mathrm{L}(3.1-5.4 \mu \mathrm{g} / \mathrm{L})$. In 4 patients, the tryptase levels were pathologically high $(>11.4 \mu \mathrm{g} / \mathrm{L})$, and in 1 case the tryptase level was $>20 \mu \mathrm{g} / \mathrm{L}$ (minor diagnostic criteria for mastocytosis).

\section{Insect sting}

Given the high frequency of beekeeping in our area, bees were the hymenoptera species most frequently associated with sting reactions $(43 \%)$.

Table 2. Clinical and Demographic Data

\begin{tabular}{|c|c|c|c|c|c|}
\hline & Patients & Total VIT & No SAR & SAR & $P$ \\
\hline No. $(\%)$ & 150 & 160 & $135(84.4)$ & $25(15.6)$ & \\
\hline Median (IQR) age, y & $45(35-55.7)$ & $45.5(35.5-56)$ & $45(35-55)$ & $46(40.5-58)$ & .39 \\
\hline Gender, MF & $106 / 44$ & $112 / 48$ & $91 / 44$ & $21 / 4$ & .88 \\
\hline cMCAS, No. (\%) & $9(6)$ & $10(6.3)$ & $6(4.4)$ & $4(16)$ & .02 \\
\hline Median (IQR) tryptase, $\mu \mathrm{g} / \mathrm{L}$ & $4.3(3.1-5.4)$ & $4.2(3.1-5.4)$ & $4.2(3.1-5.4)$ & $4.7(3.1-6.3)$ & .24 \\
\hline Median (IQR) total IgE, IU/mL & $95.9(38-224.5)$ & $102(38-231)$ & $109.5(43-253)$ & $73(32-143)$ & .1 \\
\hline $\begin{array}{l}\text { Müller grades, No. }(\%)^{\mathrm{a}} \\
\text { I } \\
\text { II } \\
\text { III } \\
\text { IV }\end{array}$ & $\begin{array}{l}47(31) \\
24(16) \\
53(35) \\
28(18)\end{array}$ & $\begin{array}{l}49(31) \\
24(15) \\
58(36) \\
28(18)\end{array}$ & $\begin{array}{l}43(32) \\
23(17) \\
47(35) \\
22(16)\end{array}$ & $\begin{array}{c}7(28) \\
1(4) \\
11(44) \\
6(24)\end{array}$ & .42 \\
\hline $\begin{array}{c}\text { Venom, No. }(\%) \\
\text { Apis } \\
\text { Polistes } \\
\text { Vespula }\end{array}$ & & $\begin{array}{l}69(43.1) \\
49(30.6) \\
42(26.3)\end{array}$ & $\begin{array}{c}50(37) \\
45(33.3) \\
40(29.6)\end{array}$ & $\begin{array}{c}19(76) \\
4(16) \\
2(8)\end{array}$ & .001 \\
\hline Specific $\operatorname{IgE}, \mathrm{kU}_{\mathrm{A}} / \mathrm{L}$ & & $7(2-19.5)$ & $6.6(2-22)$ & $8.5(2.8-15)$ & .69 \\
\hline Median pre-IT tryptase, $\mu \mathrm{g} / \mathrm{L}$ & & $4.1(3-5.5)$ & $4.1(3-5.4)$ & $4.5(2.8-6)$ & .5 \\
\hline Median post-IT tryptase, $\mu \mathrm{g} / \mathrm{L}$ & & $3.7(2.8-5.2)$ & $3.6(2.8-4.9)$ & $5(2.5-7.1)$ & .12 \\
\hline Tryptase behavior, \% up & & 13.3 & 10.5 & 64 & $<.001$ \\
\hline
\end{tabular}

Abbreviations: cMCAS, clonal mast cell activation syndrome; Pre-IT tryptase, tryptase value on the first day of VIT, before administration of the first dose; Post-IT tryptase, tryptase value after administration of the last dose on the first day of VIT; SAR, systemic adverse reaction; Tryptase behaviour \% up, percentage of VIT with a post-IT tryptase value higher than pre-IT tryptase value; VIT, Venom immunotherapy.

aTwo patients developed allergic reactions with 2 different hymenoptera stings; the Müller grade was different depending on the culprit insect. 


\section{Venom Immunotherapy}

A total of 160 VITs were administered. Ten patients received double VIT: in 8 double-sensitized patients because it was not possible to identify the culprit insect (Polistes and Vespula), and in 2 patients who developed systemic allergic reactions with 2 different hymenoptera stings (Apis and Polistes).

Tryptase was measured on the first day of VIT in 158 treatments; compared with the pre-IT tryptase value, levels decreased after the 4 doses of VIT (post-IT tryptase) in $87 \%$ of the treatments. The average percent decline was $11.2 \%$.

\section{Systemic Adverse Reactions to Immunotherapy}

A total of 56 systemic adverse reactions were recorded in 25 VITs (15.6\% of total VITs) administered to 25 patients ( 21 men and 4 women, with a median age of 46.7 years). Fourteen of the 25 patients experienced a single SAR. Most of these patients $(76 \%)$ were receiving bee VIT, compared with $37 \%$ of bee VIT in the non-SAR group $(P<.001)$.

\section{Severity and Timing of the Reaction}

Half of all SARs were grade $1(52 \%)$, with no need for treatment in $45 \%$. Severe reactions (grades 3 and 4 ) accounted for $21.4 \%$ of all SARs (10 patients; $6.25 \%$ of all VIT). Onset of SAR was during the build-up phase in 18 of the 25 patients (72\%). Of the 56 reactions, $46.4 \%$ took place during the buildup doses and 53.6\% during the maintenance doses (Table 3) in 18 and 12 patients, respectively. Five patients developed SAR during both the build-up and the maintenance phases. Ten patients experienced a SAR on the first day of VIT: 9 experienced a single SAR and 1 patient experienced 2 reactions (cutaneous pruritus with 2 doses). Nine of these SAR were grade 1, as shown in Table 3.

\section{Clonal Mast Cell Activation Syndrome}

Three patients diagnosed with cMCAS or SM received bee VIT and 6 received vespid VIT (1 patient was treated with both Vespula and Polistes VIT). All 3 bee venom-allergic patients developed SAR: 2 had severe grade 4 reactions, and 1 had a mild reaction (facial flushing). Only 1 out of 6 vespid VIT in patients with cMCAS experienced a SAR (14\%). Altogether, 4 out of 10 VITs $(40 \%)$ administered to the 9 patients with cMCAS caused SARs compared with $14 \%$ of VITs in 141 patients with no cMCAS $(P=.02)$. All patients but one were diagnosed with SM or cMCAS after the allergic reaction to the hymenoptera sting.

\section{Tryptase}

There was no significant association between SAR and baseline tryptase levels (median tryptase was $4.2 \mu \mathrm{g} / \mathrm{L}$ in the SAR group vs $4.7 \mu \mathrm{g} / \mathrm{L}$ in the non-SAR group; $P=.24)$. We found no differences using a cut-off point of $5 \mu \mathrm{g} / \mathrm{L}(40.8 \%$ in the SAR group vs $33.8 \%$ in the non-SAR group, $P=.23$ ) or using a cut-off point of $11.4 \mu \mathrm{g} / \mathrm{L}(1.5 \%$ in the SAR group vs $8 \%$ in the non-SAR group; $P=.055$ ).

However, in 16 out of 25 patients $(64 \%$; $95 \% \mathrm{CI}, 45.2 \%$ $82.8 \%$ ) who developed SAR, the post-IT tryptase value on the first day of VIT was higher than the pre-IT tryptase value (Figure). The median increase in tryptase was 19\% in these 16 patients, although only 5 of them developed a SAR on that day, and 4 out of these 5 patients had a grade 1 reaction. We found

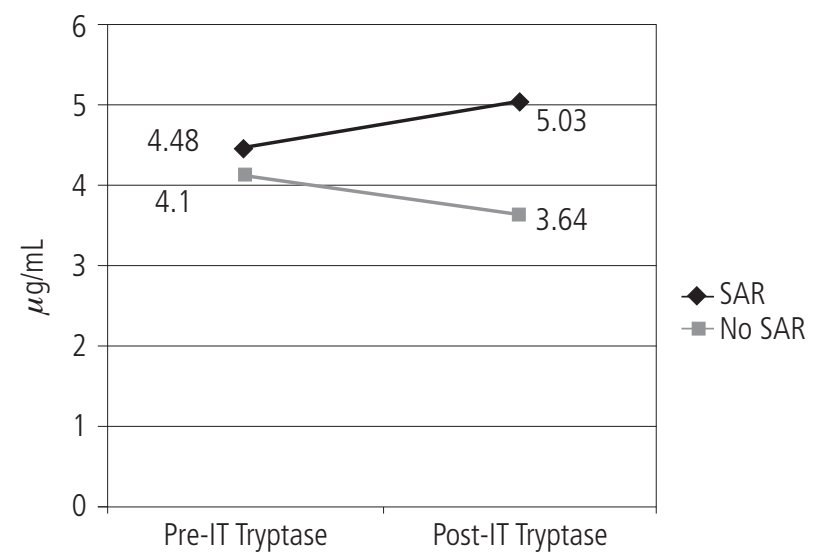

Figure. Median pre- and post-IT tryptase values on the first day of VIT in patients with and without systemic adverse reactions. A total number of 160 VIT were included: 25 with SAR, 135 with no SAR. SAR indicates systemic adverse reaction; Pre-IT tryptase, tryptase value on the first day of VIT, before administration of the first dose; Post-IT tryptase, tryptase value after administration of the last dose on the first day of VIT.

Table 3. Systemic Adverse Reactions According to Day of Onset ${ }^{\mathrm{a}}$

\begin{tabular}{lccccc}
\hline & Grade 1 & Grade 2 & Grade 3 & Grade 4 & Grade 5 \\
\hline Total (\%) & $29(51.8 \%)$ & $15(26.8 \%)$ & $5(8.9 \%)$ & $7(12.5 \%)$ & $0(0 \%)$ \\
Build-up doses & 9 & 1 & & - & - \\
$\quad$ Day 1 & 9 & - & 2 & 4 & - \\
$\quad$ Day 8 & - & - & - & 3 & - \\
Maintenance doses & 11 & 14 & 2 & - & - \\
$\quad$ Day 22 & & & & \\
$\quad$ Subsequent doses & & & & & \\
\hline
\end{tabular}

asystemic adverse reactions graded in accordance with the World Allergy Organization classification of Cox et al [21]. 
Table 4. Variables and Their Association With Systemic Adverse Reactions During Venom Immunotherapy

\begin{tabular}{lcccccc}
\hline Variable & Total No. & No SAR, $\%$ & SAR, $\%$ & RR & $95 \%$ CI & $P$ Value \\
\hline Bee venom & 69 & 37 & 76 & 4.17 & $1.76-9.89$ & .001 \\
cMCAS & 9 & 4.4 & 16 & 2.85 & $1.21-6.72$ & .02 \\
Baseline tryptase $>11.4^{\mathrm{a}}$ & 4 & 1.5 & 8 & - & - & .055 \\
Tryptase increase & 21 & 10.5 & 64 & 7.59 & $3.72-15.48$ & $<.001$
\end{tabular}

Abbreviations: cMCAS, clonal mast cell activation syndrome; RR, risk ratio; SAR, systemic adverse reaction; Tryptase increase: Tryptase value on the first day of VIT after the last dose is higher than the value prior to the first dose.

'The RR was not calculated because there was no significant association (P>.05), probably as a result of the small number of patients with this variable.

a significant association between a slight increase in tryptase level on the first day of VIT and the development of future SAR (RR, 7.6; 95\%CI, 3.7-15.5; $P<.001$ ) (Table 4). Such an increase was independent of the day of symptom onset, the severity of the SAR, and the baseline ST value. Conversely, in patients who did not develop SAR, a mean $12 \%$ decrease in ST concentration was found when post-IT and pre-IT tryptase values were compared. In fact, when post-IT tryptase values were higher than pre-IT values, the average rate of SAR was $53 \%$ compared with only $7 \%$ in patients whose post-IT tryptase values were unchanged or lower than pre-IT values $(P<.001)$. There were no significant differences in tryptase behavior between patients with and without cMCAS.

\section{Venom}

Analysis of different venom types revealed a higher risk of SAR in patients receiving bee VIT (RR, 7.8; 95\%CI, 3.58$17)$ than in those receiving vespid VIT (RR, $0.42 ; 95 \% \mathrm{CI}$, 0.18-0.99) $(P<.001)$.

\section{Discussion}

In this study, we report the results of an analysis of variations in tryptase levels on the first day of VIT and the association with SAR during VIT. Serum tryptase is a good marker of individual mast cell load or mast cell activation at a specific point in time [1]. The current standard assay for ST measures both inactive tryptase (pro- $\alpha / \beta$-tryptase, which reflects genetic factors and individual mast cell load) and mature active $\beta$-tryptase, (which is stored in mast cell granules and released upon mast cell activation) $[23,24]$. Baseline tryptase value was not associated with SAR in our study, even when different cut-off points were considered; no differences were detected with a cut-off point of $5 \mu \mathrm{g} / \mathrm{L}(P=.23)$ or a cut-off point at the upper limit of normal, $11.4 \mu \mathrm{g} / \mathrm{L}(P=.055)$. Several studies have associated elevated baseline ST levels with the occurrence or likelihood of SM [25,26], a higher risk of severe sting reactions [3,5], and an increase in SAR to VIT [27]. Low levels have been associated with alcohol consumption $[27,28]$. Elevated ST levels have been reported in $7 \%-11 \%$ of patients with hymenoptera venom allergy $[2,4]$. In our sample, only 4 patients had an ST level $>11.4 \mu \mathrm{g} / \mathrm{L}(2.6 \%$ of all VITs); this rate is clearly lower than those described by other authors. Only in 1 patient was ST above $20 \mu \mathrm{g} / \mathrm{L}$, a value that is considered a minor criterion for mastocytosis according to the WHO [17]. As the diagnosis of SM and/or cMCAS was proven in 9 patients through a bone marrow biopsy, we can state with certainty that baseline ST level is not a useful predictor of cMCAS in the present study population, as previously described $[2,18]$. cMCAS is sometimes an early stage of indolent types of SM, with a lower mast cell burden. Consequently, baseline ST levels might be normal. Therefore, clinical suspicion is mandatory for diagnosis $[18,19]$. Lifelong immunotherapy is recommended for these cMCAS patients [29,30].

Separate analysis of bee and vespid VIT revealed a significant association with SAR to venom; all patients with cMCAS who were treated with bee VIT experienced SAR, compared with the $14.3 \%$ of reactors to vespid VIT $(P=.004)$. While the small number of patients with mastocytosis or cMCAS in our study ( 6 patients: 3 received bee VIT and 6 vespid VIT) precludes further conclusions, it seems that SAR should only be expected in patients with SM treated with bee VIT, in contrast with data from Central Europe, which associated SAR with vespid VIT [5]. Based on these results, we administer cromoglicate to patients with a high suspicion of cMCAS prior to the onset of VIT, especially when they receive bee VIT.

Although baseline tryptase value was not associated with SAR in our sample, we did find very significant differences with respect to tryptase variations on the first day of VIT. A significant decline in baseline ST of about $2.5 \%$ per year has been reported during VIT [6]. Conversely, in healthy individuals, ST increases linearly with age by about $1.3 \%$ per year [4]. In the present study, we found a similar decline on the very first day of VIT in $87 \%$ of treatments, in which the pre-IT tryptase value was higher than the level recorded after the fourth VIT dose (post-IT tryptase). In our sample, we found a median reduction in ST of $12 \%$ on the first day of VIT in patients who did not have SAR compared with a median increase of $19 \%$ in those who developed SAR $(P<.001)$. DugasBreit et al [7] measured ST at 20 minutes, 90 minutes, and 18 hours after a sting challenge test in 20 patients and found a significant drop in ST from baseline levels both at 20 minutes $(-18 \%)$ and 90 minutes $(-30 \%)$ after the sting in patients who did not develop a SAR, with a return to baseline levels at 18 hours. The results were similar in controls who had not been stung. The one patient with a mild post-sting SAR showed a slight increase in ST concentration from baseline. The authors concluded that this ST decrease in patients receiving VIT could 
represent a natural circadian variation with lower levels in the afternoon and higher levels in the morning and suggest that a slight decrease or unchanged ST concentration after challenge are associated with successful therapy. The decrease in tryptase concentrations on day 1 of VIT in the nonreactors seems to be a reflection of the normal circadian decrease. It is noteworthy that all blood samples were collected in the morning, with a 3- to 3.5-hour time interval between them, while Dugas-Breit et al $[6,7]$ collected the first blood sample in the morning (at 09:00) and the second in the afternoon (between 14:20 and 15:20). In both studies by these authors, as in our study, the decrease in ST was found to be independent of the initial baseline tryptase value.

As for underlying mechanisms, VIT induces a tolerant state in peripheral $\mathrm{T}$ cells that is initiated by the actions of mediators such as IL-10 [31]. It has been postulated that IL-10 may also decrease mast cell density and growth and might thus reduce baseline ST during VIT [32,33]. While an increment in IL-10 levels 24 hours after initiation of VIT has been reported [34], the exact timing of onset of these changes is not known; it seems speculative to think that IL-10 can play a role in this early decrease in tryptase.

These variations could actually be a consequence of circadian changes, and it was clearly demonstrated in our study, as in previous investigations, that such changes are observed in both the short and the long term and that this finding is desirable as a reflection of good tolerance to treatment and of VIT efficacy.

We observed that this downward trend is reversed in most patients who develop SAR during VIT, regardless of the day of onset, even with grade 1 reactions. In anaphylaxis, the proportion of elevated tryptase values has been described as low in grade 1 reactions ( $0 \%$ ) and grade 2 reactions (4\%) [35]. In fact, in the present study, a pre-IT tryptase value that was lower than a post-IT tryptase value was the major risk factor for SAR (RR, 7.6; 95\% CI, 3.7-15.5; $P<.001$ ). The risk ratio increases to 7.8 in bee venom-allergic patients $(95 \% \mathrm{CI}, 3.58$ $17 ; P<.001)$.

It would be of interest to obtain accurate details on the behavior of $\beta$-tryptase, as well as of other mast cell markers, such as chymase and carboxypeptidase. Perhaps this would clarify the pathophysiological mechanisms responsible for our findings.

\section{Conclusions}

We conclude that an increase in tryptase levels on the first day of VIT is an independent variable that is strongly associated with a high risk of future SAR. It is independent of the day VIT is scheduled, SAR, the severity of the reaction, and the baseline tryptase value.

Recording variations in tryptase in response to VIT is a simple biomarker that could improve patients' safety.

The presence of SM or cMCAS is a risk factor for developing SAR with VIT and was related to bee VIT in our study.

\section{Acknowledgments}

We would like to thank David Rodriguez from Diater Laboratories for his help with the statistical analysis.

\section{Funding}

The authors declare that no funding was received for the present study.

\section{Conflicts of Interest}

Some authors belong to the Spanish Thematic Networks and Co-operative Research Centers ARADyAL (Center RD16/0006/0023, A Vega Castro, JM Beitia, R Cárdenas, and MB Mateo, and Center RD16/0006/0015, C Blanco), which is supported by Instituto de Salud Carlos III (ISCIII) and cofunded by Fondo Europeo de Desarrollo Regional-FEDER.

\section{Previous Presentation}

The data included in this manuscript were presented in poster format during the European Academy of Allergy and Clinical Immunology (EAACI) Annual Congress in Helsinki, Finland, June 2017.

\section{References}

1. Schwartz LB, Metcalfe DD, Miller JS, Earl H, Sullivan T. Tryptase levels as an indicador of mast-cell activation in systemic anaphylaxis and mastocytosis. N Engl J Med. 1987;316:16226.

2. Bonadonna P, Perbellini O, Passalacqua G, Caruso B, Colaross $S$, Dal FD, et al. Clonal mast cell disorders in patients with systemic reactions to Hymenoptera stings and increased serum tryptase levels. J Allergy Clin Immunol. 2009;123:6806.

3. Haeberli G, Bronnimann M, Hunziker T, Muller U. Elevated serum tryptase and Hymenoptera venom allergy: relation to severity of sting reactions and to safety and efficacy of venom immunotherapy. Clin Exp Allergy. 2003;33:1216-20.

4. Kucharewicz I, Bodzenta-Lukaszyk A, Szymanski W, Mroczko B, Szmitkowski M. Basal serum tryptase level correlates with severity of hymenoptera sting and age. Allergy. 2010;65:91923.

5. Ruëff F, Przybilla B, Biló MB, Müller U, Scheipl F, Aberer W et al. Predictors of severe systemic anaphylactic reactions in patients with Hymenoptera venom allergy: importance of baseline serum tryptase-a study of the European Academy of Allergology and Clinical Immunology Interest Group on Insect Venom Hypersensitivity. J Allergy Clin Immunol. 2009;124(5):1047-54.

6. Dugas-Breit S, Przybilla B, Dugas M, Arnold A, Pfundstein $G$, Küchenhoff $H$, Ruëff $F$. Serum concentration of baseline mast cell tryptase: evidence for a decline during long-term immunotherapy for Hymenoptera venom allergy. Clin Exp Allergy. 2010;40:643-9.

7. Dugas-Breit S, Przybilla B, Schöpf P, Ruëff F. Possible circadian variation of serum mast cell tryptase concentration. Allergy. 2005;60:689-92.

8. Golden DBK. Insect sting allergy and venom immunotherapy: A model and a mystery. J Allergy Clin Immmunol. 2005;115:43947.

9. Muller U, Mosbech H, editors. Position paper. Immunotherapy with Hymenoptera venoms. Allergy. 1993;48(Suppl 14):37-46 
10. Bonifazi F, Jutel M, Bilo BM, Birnbaum J, Muller U. Prevention and treatment of hymenoptera venom allergy: guidelines for clinical practice. Allergy. 2005;60(12):1459-70.

11. Mosbech H, Müller U. Side-effects of insect venom immunotherapy: results from an EAACl multicenter study. European Academy of Allergology and Clinical Immunology. Allergy. 2000;55(11):1005-10.

12. Ruëff F, Przybilla B, Biló MB, Müller U, Scheipl F, Aberer W, et al. Predictors of side effects during the buildup phase of venom immunotherapy for Hymenoptera venom allergy: the importance of baseline serum tryptase. J Allergy Clin Immunol. 2010;126(1):105-11.

13. Ruiz $B$, Serrano $P$, Moreno C. IgE-Api $m 4$ is useful to identify a particular phenotype of allergy to bee venom. J Investig Allergol Clin Immunol. 2016; 26(6):355-61.

14. Korosec P, Ziberna K, Silar M, Dezman M, Celesnik Smodis N, Rijavec M, et al. Immunological and clinical factors associated with adverse systemic reactions during the build-up phase of honeybee venom immunotherapy. Clin Exp Allergy. 2015;45:1579-89.

15. Biló BM, Rueff F, Mosbech H, Bonifazi F, Oude-Elberink JN; EAACl Interest Group on Insect Venom Hypersensitivity. Diagnosis of Hymenoptera venom allergy. Allergy. 2005;60(11):1339-49.

16. Sturm GJ, Varga E-M, Roberts $G$, Mosbech $H$, Bilò MB, Akdis $C A$, et al. EAACl guidelines on allergen immunotherapy: Hymenoptera venom allergy. Allergy. 2017;00:1-20.

17. Valent $P$, Horny HP, Escribano L, Longley BJ, Li CY, Schwartz LB, et al. Diagnostic criteria and classification of mastocytosis; a consensus proposal. Leukocyte Res. 2001;25:603-25.

18. Sonneck K, Florian S, Müllauer L, Wimazal F, Födinger M, Sperr WR, et al. Diagnostic and subdiagnostic accumulation of mast cells in the bone marrow of patients with anaphylaxis: monoclonal mast cell activation syndrome. Int Arch Allergy Immunol. 2007;142:158-64.

19. Alvarez-Twose I, González de Olano D, Sánchez-Muñoz $L$, Matito A, Esteban-López MI, Vega A, et al. Clinical, biological, and molecular characteristics of clonal mast cell disorders presenting with systemic mast cell activation symptoms. J Allergy Clin Immunol. 2010;125(6):1269-78.

20. Sánchez-Machín I, Moreno C, González R, Iglesias-Souto $J$, Pérez E, Matheu V. Safety of a 2-visit cluster schedule of venom immunotherapy in outpatients at risk of life-threatening anaphylaxis. J Investig Allergol Clin Immunol. 2010;20(1):91-2.

21. Cox L, Larenas-Linnemann D, Lockey RF, Passalacqua G, editors. Speaking the same language: the World Allegy Organization subcutaneous immunotherapy systemic reaction grading system. J Allergy Clin Immunol. 2010;125:569-74.

22. Simons FER, Ardusso LRF, Bilò MB, El-Gamal YM, Ledford DK, Ring J, et al. World Allergy Organization anaphylaxis guidelines: Summary. J Allergy Clin Immunol. 2011;127:58793.

23. Schwartz $L B$, Bradford TR, Rouse $C$, Irani AM, Rasp G, Van der Zwan, et al. Development of a new, more sensitive immunoassay for human tryptase: use in systemic anaphylaxis. J Allergy Clin Immunol. 1994;14:190-204.

24. Müller U. Elevated baseline serum tryptase, mastocytosis and anaphylaxis. Clin Exp Allergy. 2009:39:620-2.
25. González-de-Olano D, Alvarez-Twose I, Vega A, Orfao A, Escribano L. Venom immunotherapy in patients with mastocytosis and hymenoptera venom anaphylaxis. Immunotherapy. 2011May;3(5):637-51.

26. Valent $P$, Horny HP, Escribano L, Longley BJ, Li CY, Schwartz LB, et al. Diagnostic criteria and classification of mastocytosis; a consensus proposal. Leukocyte Res. 2001;25:603-25.

27. Carballada F, Alonso M, Vizcaino L, Coutinho V, Núñez R, Vidal $C$, et al. Serum tryptase concentrations in beekeepers with and without hymenoptera venom allergy. J Invest Allergol Clin Immunol . 2013;23:30-6.

28. Beceiro C, Campos J, Valcarcel MA, Fenger RV, Lojo S, Linnemberg $A$, et al. Serum concentrations of mast cell tryptase are reduced in heavy drinkers. Alcohol Clin Exp Res. 2015;39:672-8.

29. Bonadonna P, Lombardo C, Zanotti R. Mastocytosis and allergic diseases. J Investig Allergol Clin Immunol. 2014;24(5):28897.

30. Alfaya Arias T, Soriano Gómis V, Soto Mera T, Vega Castro A, Vega Gutiérrez JM, Alonso Llamazares A, et al; Hymenoptera Allergy Committee of the SEAIC. Key Issues in Hymenoptera Venom Allergy: An Update. J Investig Allergol Clin Immunol. 2017;27(1):19-31.

31. Akdis CA, Blesken T, Akdis M, Wuetrich B, Blaser K. Role of interleukin 10 in specific immunotherapy. J Clin Invest. 1998:102:98-106.

32. Akdis CA, Akdis M. Mechanisms and treatment of allergic disease in the big picture of regulatory cells. J Allergy Clin Immunol. 2009;123:735-46.

33. Speiran K, Bailey DP, Fernando J, Macey M, Barnstein B, Kolawole $M$, et al. Endogenous supresion of mast cell development and survival by IL-4 and IL-10. J Leukocyte Biol. 2009;85:826-36.

34. Riccio AM, Saverino D, Pesce G, Rogkakou A, Severino M, Bonadonna $P$ et al. Effects of different up-dosing regimens for hymenoptera venom immunotherapy on serum CTLA-4 and IL-10. PLoS One. 2012;7(6):e37980.

35. Vadas P, Perelman B, Liss G. Platelet-activating factor, histamine and tryptase levels in human anaphylaxis. J Allergy Clin Immunol. 2013;131:144-9.

\section{Manuscript received December 13, 2017; accepted for publication March 26, 2018.}

\section{- Arantza Vega Castro}

Allergy Service, Hospital Universitario de Guadalajara

$\mathrm{C} /$ Donante de sangre, $\mathrm{s} / \mathrm{n}$

19002 Guadalajara, Spain

E-mail: avega@sescam.jccm.es 